\title{
THE ROLE OF PLASMA D - DIMER AS PROGNOSTIC MARKER IN CHILDREN WITH TRAUMATIC BRAIN INJURY
}

\author{
Khaled M. Abd El-Twab, Hala M. Foaud*, John R. youssef**, Hala G. Metwally**** \\ * Professor of Pediatrics, Faculty of Medicine Cairo University \\ ** Lecturer of Pediatrics, Faculty of Medicine Cairo University \\ *** Professor of Clinical Pathology, Faculty of Medicine Cairo University.
}

\begin{abstract}
Objectives: To investigate the value of plasma D-dimer as a prognostic marker in severe traumatic brain injury in children and to compare the results of plasma $\mathrm{D}$ - dimer level in plasma and the clinical condition of the case and the results of its routine laboratory investigations.

Methods: The study was carried out on 64 head trauma children 46 cases and 20 controls of both sexes, who admitted to pediatric intensive care unit in Alharam hospital in Giza.All children patients had full history, vital sign, general examination, complete neurological examination, GCS or PGCS, cranial CT scan, abdominal ultrasonography, full radiological studies, plasma D-dimer on admission, the 3rd day and at 14th day, INR, PT, APTT. on admission, the 3rd day and at 14th day, routine laboratory investigations on admission as CBC, CRP, Liver function test, Urea, Creatinine, Blood glucose, Na, K and Arterial blood gas analysis.

Results: GCS improved significantly in the favorable group but not in the unfavorable group. D-dimer mean values were significantly higher in the unfavorable group more than the favorable group. D-dimer is correlated with mortality and can predict poor patient outcome. D-dimer have inverse relation with GCS and. PT, aPTT, INR, and Concentration mean values were significantly higher in the unfavorable group than in the favorable group.

Conclusion: GCS or PGCS has evident role in evaluation and assessment of TBI especially in acute stage and gives excellent idea about the prognoses of TBI. D-dimer is a good marker to predict outcome in TBI \& it has an inverse correlation with GCS or PGCS. PT, aPTT, INR and Concentration have some role in TBI and their values increase in the acute stage of TBI.
\end{abstract}

Key words: Children, TBI, D-dimer, markers.

\section{INTRODUCTION}

T raumatic brain injury (TBI) is a leading cause of death and disability around the globe and presents a major worldwide social, economic, and health problem. It is the number one cause of coma. And is the leading cause of brain damage in children and young adults. About $2 \%$ of all emergency department visits are due to head injury. It is the leading cause of death among people less than 24 years of age. ${ }^{(1)}$

Also traumatic brain injury (TBI) is the leading cause of death and disability in children. Statistical analyses shows that almost half of patients with a TBI each year in the United Kingdom are children under 16 years, and approximately one third of the patients with cranial trauma per year in the United States are children aged between 0 and 14 years old. ${ }^{(2)}$

The most common causes of TBI in children: falls, child abuse, motor vehicle accidents sport accidents, assaults, and instrumental delivery. Regarding age distribution of TBI, there are two risk groups: the first group aged between 0 and 4 years old, and the second 15-19 years old. Boys seem to be affected twice the rate of girls. ${ }^{(3)}$

Traumatic pathology during the first 3 years of life is completely different when compared with adults. Raimondi emphasized the differentials between children and adults' pathology: "children are not young adults". ${ }^{(2)}$

In developed countries, pediatric trauma mortality still represents more than half of all childhood fatalities: 18 times more common than brain tumors.However, many aspects of pediatric neurotrauma still remain unclear as the literature focusing on the pediatric population is very limited. In fact, guidelines for management of pediatric TBI were mainly derived from adult guidelines. ${ }^{(4)}$

Several prognostic factors, such as age group, gender, pupillary reactivity, Glasgow Coma Score (GCS) on admission, serum glucose level, total white blood cell (TWBC) counts, platelet counts, coagulation derangement, computerized tomography (CT) scan features and grading, have been validated in various studies to predict outcome in adult neurotrauma. However, the impacts of these factors are poorly understood in pediatric TBI. The predictive value of GCS was reported to be low in one local pediatric TBI study. Traumatic brain injury is conventionally graded on a severity continuum ranging from mild to severe. Injuries on the more severe end of this 
continuum are associated with significant morbidity and mortality. ${ }^{(5)}$

As such, considerable attention has been devoted to their understanding and management. Both clinical and surveillance definitions indicate, however, that mild TBI accounts for $80-90 \%$ of all treated cases. ${ }^{(6)}$

The property of the circulation whereby blood retains its fluidity within the vasculature while the system simultaneously prevents excessive blood loss upon injury is known as hemostasis. In response to vascular injury, clotting reactions are initiated to create an insoluble fibrin-platelet plug at the site of the vessel wall defect, arrest blood loss, and eventually restore vascular integrity. This activation leads to the release of the various substances needed in platelet aggregation and initiation of the coagulation cascade, resulting in the formation of cross-linked fibrin assuring a firm clot at the injury site. ${ }^{(7)}$

During fibrinolysis, plasmin starts cleaving fibrinogen and soluble fibrin. Degradation of cross-linked fibrin results in formation of various fibrin fragments. The smallest oligomer is fragment D-Dimer. The measurement of D-Dimer reflects intravascular levels of fibrin turnover, without significant interference from fibrinogen or soluble fibrin degradation products, and confirms that both thrombin generation and plasmin generation have occurred. D-Dimer levels have certain advantages over other measures of thrombin generation, because it is resistant to ex vivo activation, relatively stable, and has a long half-life. In addition, D-Dimer assays can be performed easily with standard laboratory equipments. ${ }^{(8)}$

D- Dimer level is very rarely elevated in healthy individuals and valuable as a negative predictor to rule out $>97 \%$ of the cases. In clinically suspected TBI, D-Dimer has gained widespread clinical use as a parameter for detection of in vivo fibrin formation in the presence of a thrombotic condition. Plasma DDimer levels, however, may increase in many illnesses and physiological conditions associated with many conditions like clots, DIC, post operative, trauma, sepsis, venous thromboembolism, major hemorrhage, increasing age, pregnancy, racial variation. It has also some false negative results in case of anti-coagulant treatment. However there has been a clear relationship found between high levels of plasma D-dimer and poor patient prognosis and poor outcome, and mortality, so several studies tried to make D-dimer an early prognostic marker for TBI severity and poor patient prognosis and mortality. (7)

\section{AIM OF THE WORK}

To investigate the value of plasma D-dimer as a prognostic marker in severe traumatic brain injury in children and to compare the results of plasma D- Dimer level in plasma and the clinical condition of the case and the results of its routine laboratory investigations.

PATIENTS and METHODS

The study was carried out on 64 head trauma children 46 cases and 20 controls of both sexes, who admitted to pediatric intensive care unit in Alharam hospital in Giza. The selected patients had the following inclusion and exclusion criteria:

\section{A- Inclusion criteria:}

Isolated non surgical head trauma patients with any of the following CT brain findings:

1 - Brain contusion or laceration.

2- Intra cerebral hemorrhage.

3- Subarachnoid hemorrhage.

4- Intra ventricular hemorrhage.

5- Patients with extradural or subdural hematoma.

B- Exclusion criteria:

1-Patients aged less than 1 year old and more than 16 years old.

2- Isolated brain edema.

3- Patients who received any type of blood products during the first 24 hours of admission.

4- Patients who were operated for hematoma evacuation.

5- Poly traumatized Patients.

All the brain injured children patients who were admitted to pediatric intensive care unit in Alharam hospital in Giza were fully examined and investigated to fulfill the criteria of inclusion and exclusion in the study. Informed consent was taken from their legal guardians, and approval of the local ethical committee was obtained.

\section{A- Examination and investigation}

All children patients were examined and investigated as follow:

1- Full history including age, sex and weight were taken with special emphasis on the onset of head trauma and the mechanism of injury and the time lapse since head injury till hospital admission.

2- Vital signs: Blood pressure, pulse, respiratory rate and temperature.

3- General examination: Head, neck, chest, abdomen and extremities. .

4- Complete neurological examination: was done on admission and daily, GCS or PGCS, sensory and motor examination and pupillary reflexes and cranial nerves examination were done.

5-Cranial CT scanning was done to all patients on admission and was done for regular follow up and in special circumstances when the patient's condition had sudden unpredictable changes in his 
GCS or PGCS in consistence with his treating plan.

6- Abdominal ultrasonography was done to all patients.

7- Full radiological studies to detect possible extra-cranial injuries that may compromise our study.

8- Plasma D-Dimer on admission, the 3rd day and at 14 th day.

9- INR, PT, APTT. on admission, the 3rd day and at 14 th day

10- Routine laboratory investigations on admission as CBC, CRP, Liver function test, Urea, Creatinine, Blood glucose, $\mathrm{Na}$ and $\mathrm{K}$.

11- Arterial blood gas analysis was done when needed.

\section{B- Measurements and Timing}

Venous sampling: Venous blood sample $2 \mathrm{ml}$ blood was taken for estimation of D- dimer and PT, aPTT and INR, the sample volume was put in citrated tubes and was also sent directly to the laboratory.

\section{C- Method of processing:}

- D-dimer was processed using Pathfast D-dimer test kits manufactured by IVD for in vitro diagnostics company and the device used is chemiluminescent enzyme immunoassay (CLEIA). ${ }^{(9)}$
- PT was processed using Paistinex thromboplastin for use of prothrombin time test manifectured by Biodata Corporation, and INR was calculated using the formula. ${ }^{(10)}$

- INR $=$ Patient prothrombin time $(\mathrm{PT}) \div$ Mean normal prothrombin time (PT n). - aPTT was processed using liquicellin-E for aPTT determination test manifectured by BIOSTC high performance diagnostic reagents company, device used is turbodensitometeric instrument.

- D-dimer, PT, aPTT, INR was all tested on admission, on day 3 and on day 14 of the study.

\section{RESULTS}

The statistical analysis of the data was obtained in the present study was carried out using SPSS version 15 comparison between the groups of normally distributed quantitative data was analyzed using paired t-test, student t-test and F test (ANOVA) while not normally distributed quantitative data was analyzed using non parametric test such as Wilcoxon signed ranks test, Mann Whitney test and Kruskal wallis test. All the The study was carried out on 64 patients 46 cases and 20 control cases fulfilled the inclusion and exclusion criteria previously mentioned and the age of the whole study patients ranged between 1-16 years of age.

Table (1) means \pm Standard Deviation (SD) of age (by years)

\begin{tabular}{|c|c|c|c|c|c|c|c|c|}
\hline & & $\mathbf{N}$ & Minimum & Maximum & Mean & $\begin{array}{c}\text { Std. } \\
\text { Deviation }\end{array}$ & $\mathbf{t}$ & $\mathbf{P}$ \\
\hline \multirow[t]{4}{*}{ age } & Favorable & 23 & 1.25 & 13.60 & 6.3922 & 3.80005 & $t 1=1.31$ & $>0.05$ \\
\hline & Un favorable & 23 & 2.33 & 14.25 & 7.6461 & 3.63944 & $\mathrm{t} 2=0.32$ & $>0.05$ \\
\hline & Control & 20 & 2.16 & 15.33 & 8.0500 & 4.52310 & & \\
\hline & Total & 66 & 1.25 & 15.33 & 7.3315 & 3.98207 & & \\
\hline
\end{tabular}

$\mathrm{t} 1=$ favorable vs. control $\mathrm{t} 2=$ Un favorable vs. control $\quad$ One Way Anova "F" = 1.04 $\mathrm{P}>0.05$

Table (2) means \pm Standard Deviation (SD) of Wt (by kg)

\begin{tabular}{ccccccccc}
\hline & & N & Minimum & Maximum & Mean & Std. Deviation & $T$ & $P$ \\
\hline Wt & Favorable & 23 & 10.00 & 59.00 & 26.2174 & 13.11126 & $\begin{array}{c}\text { t1= } \\
0.85\end{array}$ & $>0.05$ \\
\cline { 2 - 9 } & $\begin{array}{c}\text { Un } \\
\text { favorable }\end{array}$ & 23 & 14.00 & 46.00 & 26.0870 & $\mathbf{8 . 6 3 8 7 8}$ & t2=1.1 & $>0.05$ \\
\hline Control & 20 & 14.00 & 48.00 & 29.4000 & 11.08057 & & \\
\hline Total & 66 & 10.00 & 59.00 & 27.1364 & 11.02708 & & \\
\hline
\end{tabular}

$\mathrm{t} 1=$ favorable vs. control $\mathrm{t} 2=$ Un favorable vs. control $\quad$ One Way Anova "F" $=0.598 \quad \mathrm{P}>0.05$ 
Table (3) sex distribution of the study groups

$\begin{array}{lllll}\text { study groups } & \text { Favorable } & \text { Unfavorable Control }\end{array}$

sex

sex

\begin{tabular}{ccccccccc} 
& no & $\%$ & No & $\%$ & No & $\%$ & no & \\
\hline males & 16 & 69.6 & 10 & 43.5 & 8 & 40.0 & 34 & 51.5 \\
\hline females & 7 & 30.4 & 13 & 56.5 & 12 & 60.0 & 32 & 48.5 \\
\hline Total & 23 & 100.0 & 23 & 100.0 & 20 & 100.0 & 66 & 100.0
\end{tabular}

Table (4) diagnosis of the study groups

\begin{tabular}{cccccccc}
\hline & study groups & \multicolumn{2}{c}{ Favorable } & \multicolumn{2}{c}{ Unfavorable } & \multicolumn{2}{c}{ Total } \\
\cline { 3 - 8 } Diagnoses & & no & $\%$ & No & $\%$ & no & $\%$ \\
\hline & S.D.Hg & 4 & 17.4 & 2 & 8.7 & 6 & 13.0 \\
\hline S.A.Hg & 6 & 26.1 & 2 & 8.7 & 8 & 17.4 \\
\hline I.C.Hg & 13 & 56.5 & 14 & 60.9 & 27 & 58.7 \\
\hline I.V.Hg & 0 & 0.0 & 5 & 21.7 & 5 & 10.9 \\
\hline Total & 23 & 100.0 & 23 & 100.0 & 46 & 100.0 \\
\hline
\end{tabular}

The diagnoses of the cases in the favorable group was 4 cases subdural hemorrhage (17.4\%), 6 cases subarachnoid hemorrhage (26.1\%) and 13 cases intracranial hemorrhage $(56.5 \%)$ while in the un favorable group was 2 cases subdural hemorrhage (8.7\%), 2 cases subarachnoid hemorrhage (8.7\%), 14 cases intracranial hemorrhage (60.9\%) and 5 cases interventricular hemorrhage (21.7\%).

$\underline{\text { Table (5) means } \pm \text { Standard Deviation (SD) of GCS at } 1^{\text {st }} \text { day }}$

\begin{tabular}{ccccccccc}
\hline & & N & Minimum & Maximum & Mean & $\begin{array}{c}\text { Std. } \\
\text { Deviation }\end{array}$ & T & P \\
\hline \multirow{3}{*}{$\begin{array}{c}\text { GCS } \\
1^{\text {st }} \\
\text { day }\end{array}$} & Favorable & 23 & 6.00 & 12.00 & 9.6522 & 1.61270 & t1=14.8 & $<0.001$ \\
\cline { 2 - 9 } & Unfavorable & 23 & 3.00 & 7.00 & 4.0435 & 1.18622 & t2=41.2 & $<0.001$ \\
\cline { 2 - 9 } & Control & 20 & 15.00 & 15.00 & 15.0000 & .00000 & & \\
\cline { 2 - 9 } & Total & 66 & 3.00 & 15.00 & 9.3182 & 4.60154 & & \\
\hline
\end{tabular}

$\mathrm{t} 1=$ favorable vs. control $\quad \mathrm{t} 2=$ Un favorable vs. control One Way Anova "F" $=460.19 \quad \mathrm{P}<0.001$

Table (6) means \pm Standard Deviation (SD) of GCS $14^{\text {th }}$ days

\begin{tabular}{|c|c|c|c|c|c|c|c|c|}
\hline & & $\mathbf{N}$ & Minimum & Maximum & Mean & Std.Deviation & $\mathbf{T}$ & $\mathbf{P}$ \\
\hline \multirow{4}{*}{$\begin{array}{c}\text { GCS } \\
14^{\text {th }} \\
\text { days }\end{array}$} & Favorable & 23 & 13.00 & 15.00 & 14.6957 & .63495 & $\mathrm{t} 1=2.14$ & $<0.05$ \\
\hline & Un favorable & 23 & 3.00 & 8.00 & 6.0870 & 1.59297 & $\mathrm{t} 2=24.9$ & $<0.001$ \\
\hline & Control & 20 & 15.00 & 15.00 & 15.0000 & .00000 & & \\
\hline & Total & 66 & 3.00 & 15.00 & 11.7879 & 4.31995 & & \\
\hline
\end{tabular}

$\mathrm{t} 1=$ favorable vs. control $\mathrm{t} 2=$ Un favorable vs. control One Way Anova " $\mathrm{F}$ " $=559.1 \quad \mathrm{P}<0.001$ 
Table (7) means \pm Standard Deviation (SD) of Plasma D- Dimer at the $1^{\text {st }}$ day (by $\left.\mu / L\right)$

\begin{tabular}{|c|c|c|c|c|c|c|c|c|}
\hline & & $\mathbf{N}$ & Minimum & $\begin{array}{c}\text { Maxim- } \\
\text { um }\end{array}$ & Mean & $\begin{array}{c}\text { Std. } \\
\text { Deviation }\end{array}$ & $\mathbf{T}$ & $\mathbf{P}$ \\
\hline \multirow{4}{*}{$\begin{array}{c}\text { Dimer } \\
\text { At } 1^{\text {st }} \\
\text { day }\end{array}$} & Favorable & 23 & 890.00 & 8645.00 & $4.2862 \mathrm{E} 3$ & 2398.01345 & $\mathrm{t} 1=7.53$ & $<0.001$ \\
\hline & $\begin{array}{c}\text { Un } \\
\text { favorable }\end{array}$ & 23 & 978.00 & 46778.00 & 2.7208E4 & 13884.67810 & $t 2=8.64$ & $<0.001$ \\
\hline & Control & 20 & 49.00 & 754.00 & 2.3270E2 & 189.36740 & & \\
\hline & Total & 66 & 49.00 & 46778.00 & $1.1046 E 4$ & 14552.79551 & & \\
\hline
\end{tabular}

$\mathrm{t} 1=$ favorable vs. control $\mathrm{t} 2=\mathrm{Un}$ favorable vs. control $\quad$ One Way Anova "F" $=67.76 \quad \mathrm{P}<0.001$

Table (8) means \pm Standard Deviation (SD) of Plasma D- dimer at the $14^{\text {th }}$ day (by $\left.\mu / \mathrm{L}\right)$

N $\begin{array}{llllll}\text { Minimum } & \text { Maximum } & \text { Mean } & \text { Std. } & \text { T } & \text { P }\end{array}$

Deviation

\begin{tabular}{ccccccccc}
\hline \multirow{2}{*}{$\begin{array}{c}\text { Dimer } \\
14^{\text {th }} \\
\text { days }\end{array}$} & Favorable & 23 & 271.00 & 1617.00 & $7.5261 \mathrm{E} 2$ & 355.07550 & t1=6.57 & $<0.001$ \\
\cline { 2 - 9 } & Unfavorable & 23 & 329.00 & 2316.00 & $1.3823 \mathrm{E} 3$ & $\mathbf{5 6 0 . 5 8 6 3 5}$ & t2=9.2 & $<0.001$ \\
\cline { 2 - 9 } & Control & 20 & 70.00 & 559.00 & $2.0045 \mathrm{E} 2$ & $\mathbf{1 3 0 . 0 3 8 6 5}$ & & \\
\cline { 2 - 9 } & Total & 66 & 70.00 & 2316.00 & $\mathbf{8 . 0 4 7 4 E 2}$ & $\mathbf{6 2 0 . 7 6 8 9 8}$ & & \\
\hline
\end{tabular}

$\begin{array}{llll}\mathrm{t} 1=\text { favorable vs. control } \mathrm{t} 2=\text { Un favorable vs. cntrol } & \text { One Way Anova " } \mathrm{F} "=47.33 \quad \mathrm{P}<0.001\end{array}$

Table (9) means \pm Standard Deviation (SD) ofPT at the 1st day (by second)

\begin{tabular}{|c|c|c|c|c|c|c|c|c|}
\hline & & $\mathbf{N}$ & Minimum & Maximum & Mean & Std. Deviation & $\mathbf{T}$ & $\mathbf{P}$ \\
\hline \multirow{4}{*}{$\begin{array}{c}\text { PT } \\
1^{\text {st }} \\
\text { day }\end{array}$} & Favorable & 23 & 11.70 & 17.90 & 14.3174 & 1.78978 & $t 1=6.7$ & $<0.001$ \\
\hline & Unfavorable & 23 & 14.30 & 56.60 & 26.3130 & 13.40462 & $t 2=4.97$ & $<0.001$ \\
\hline & Control & 20 & 10.00 & 13.10 & 11.3750 & .86382 & & \\
\hline & Total & 66 & 10.00 & 56.60 & 17.6061 & 10.23316 & & \\
\hline
\end{tabular}

Table (10) means \pm Standard Deviation (SD) of PT at the 14th days (by second)

\begin{tabular}{|c|c|c|c|c|c|c|c|c|}
\hline & & $\mathbf{N}$ & Minimum & Maximum & Mean & Std. Deviation & $\mathbf{T}$ & $\mathbf{P}$ \\
\hline \multirow{4}{*}{$\begin{array}{l}\text { PT } \\
14^{\text {th }} \\
\text { days }\end{array}$} & Favorable & 23 & 10.50 & 13.40 & 11.6000 & .68953 & $\mathrm{t} 1=0.67$ & $>0.05$ \\
\hline & Un favorable & 23 & 11.00 & 49.20 & 24.5870 & 10.15423 & $t 2=5.76$ & $<0.001$ \\
\hline & Control & 20 & 10.50 & 12.80 & 11.4650 & .61923 & & \\
\hline & Total & 66 & 10.50 & 49.20 & 16.0848 & 8.62749 & & \\
\hline
\end{tabular}


Table (11) means \pm Standard Deviation (SD) of aPTT at the $1^{\text {st }}$ day (by second)

\begin{tabular}{|c|c|c|c|c|c|c|c|c|}
\hline & & $\mathbf{N}$ & Minimum & Maximum & Mean & Std. Deviation & $\mathbf{T}$ & $\mathbf{P}$ \\
\hline \multirow{4}{*}{$\begin{array}{c}\text { aPTT } \\
\mathbf{1}^{\text {st }} \\
\text { day }\end{array}$} & Favorable & 23 & 30.00 & 49.60 & 37.2391 & 5.24835 & $\mathrm{t} 1=5.51$ & $<0.001$ \\
\hline & Un favorable & 23 & 27.20 & 82.00 & 53.4130 & 14.97189 & $t 2=6.87$ & $<0.001$ \\
\hline & Control & 20 & 25.20 & 34.40 & 30.0350 & 2.76354 & & \\
\hline & Total & 66 & 25.20 & 82.00 & 40.6924 & 13.55909 & & \\
\hline
\end{tabular}

$\mathrm{t} 1=$ favorable vs. control $\quad \mathrm{t} 2=$ Un favorable vs. control $\quad$ One Way Anova "F" $=34.7 \quad \mathrm{P}<0.001$

Table (12) means \pm Standard Deviation (SD) of aPTT at the $14^{\text {th }}$ day (by second)

\begin{tabular}{|c|c|c|c|c|c|c|c|c|}
\hline & & $\mathbf{N}$ & Minimum & Maximum & Mean & Std. Deviation & $\mathbf{T}$ & $\mathbf{P}$ \\
\hline \multirow{4}{*}{$\begin{array}{l}\text { aPTT } \\
14^{\text {th }} \\
\text { days }\end{array}$} & Favorable & 23 & 25.90 & 46.90 & 30.0739 & 4.57147 & $\mathrm{t} 1=0.12$ & $>0.05$ \\
\hline & Un favorable & 23 & 26.20 & 68.00 & 43.4304 & 12.01463 & $\mathrm{t} 2=4.9$ & $<0.001$ \\
\hline & Control & 20 & 26.00 & 35.00 & 29.9350 & 2.86030 & & \\
\hline & Total & 66 & 25.90 & 68.00 & 34.6864 & 9.99255 & & \\
\hline
\end{tabular}

$\mathrm{t} 1=$ favorable vs. control $\quad \mathrm{t} 2=$ Un favorable vs. control $\quad$ One Way Anova "F" $=22.43 \quad \mathrm{P}<0.001$

Table (13) means \pm Standard Deviation (SD) of HG (by g/dL)

\begin{tabular}{|c|c|c|c|c|c|c|c|c|}
\hline & & $\mathbf{N}$ & Minimum & Maximum & Mean & Std.Deviation & $\mathbf{T}$ & $\mathbf{P}$ \\
\hline \multirow[t]{4}{*}{ HG } & Favorable & 23 & 9.10 & 14.10 & 11.1261 & 1.46325 & $t 1=3.21$ & $<0.01$ \\
\hline & Un favorable & 23 & 7.80 & 13.60 & 10.6913 & 1.47615 & $\mathrm{t} 2=4.22$ & $<0.001$ \\
\hline & Control & 20 & 10.10 & 14.20 & 12.4650 & 1.24320 & & \\
\hline & Total & 66 & 7.80 & 14.20 & 11.3803 & 1.57062 & & \\
\hline
\end{tabular}

Chart (1) meens of ages

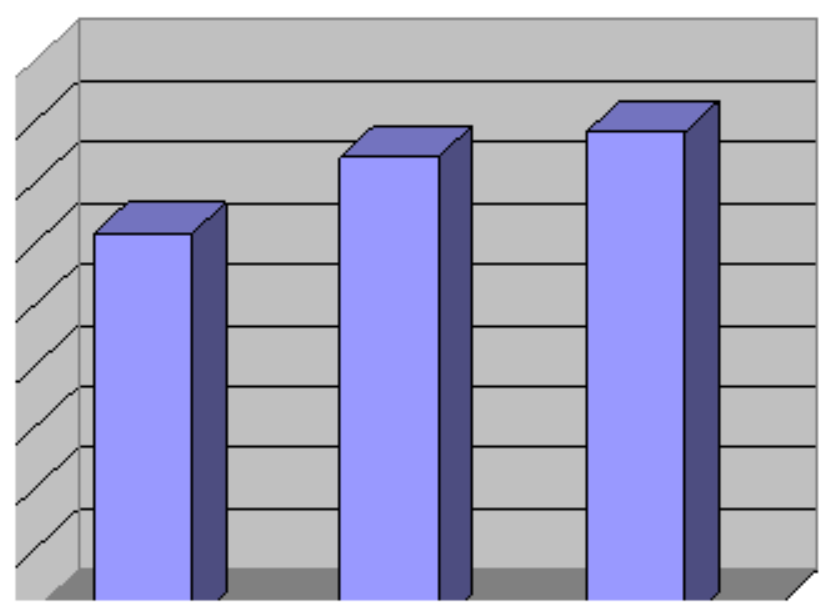

Chart (2) means of wt of study groups

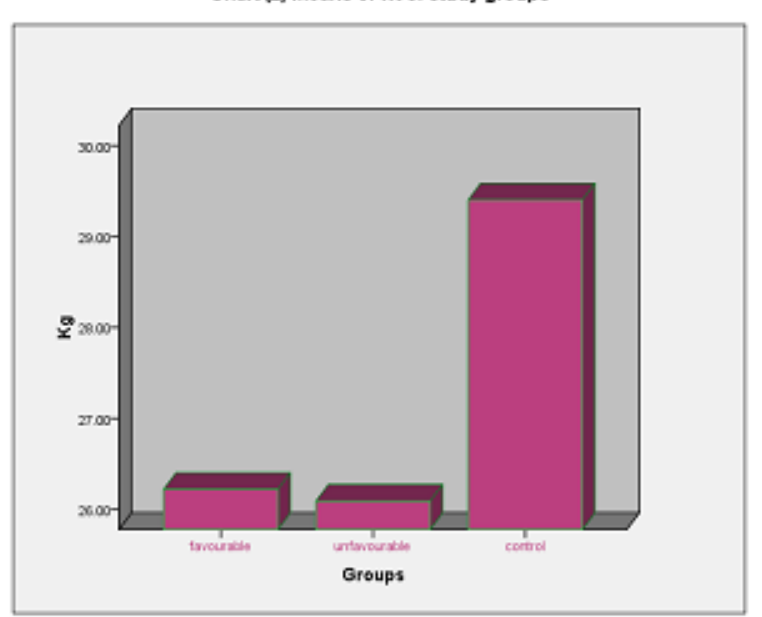




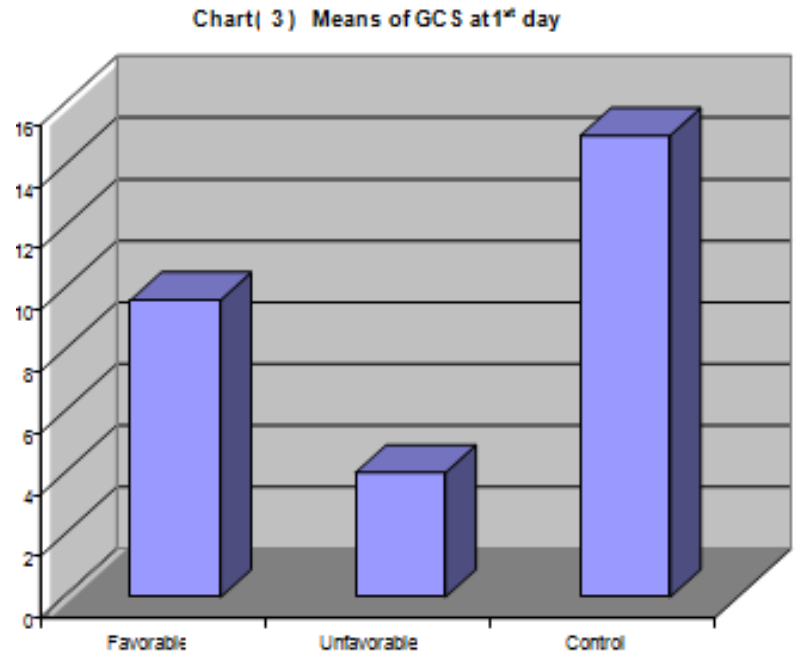

Chart (5) Meane of DIMER at $1^{1 x}$ day

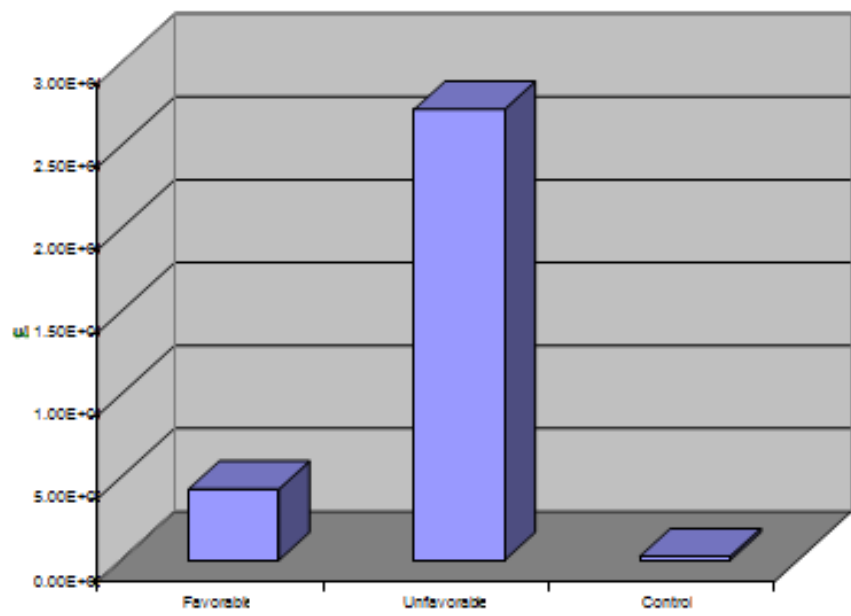

Chart (7) Means of PT at $1^{4}$ day

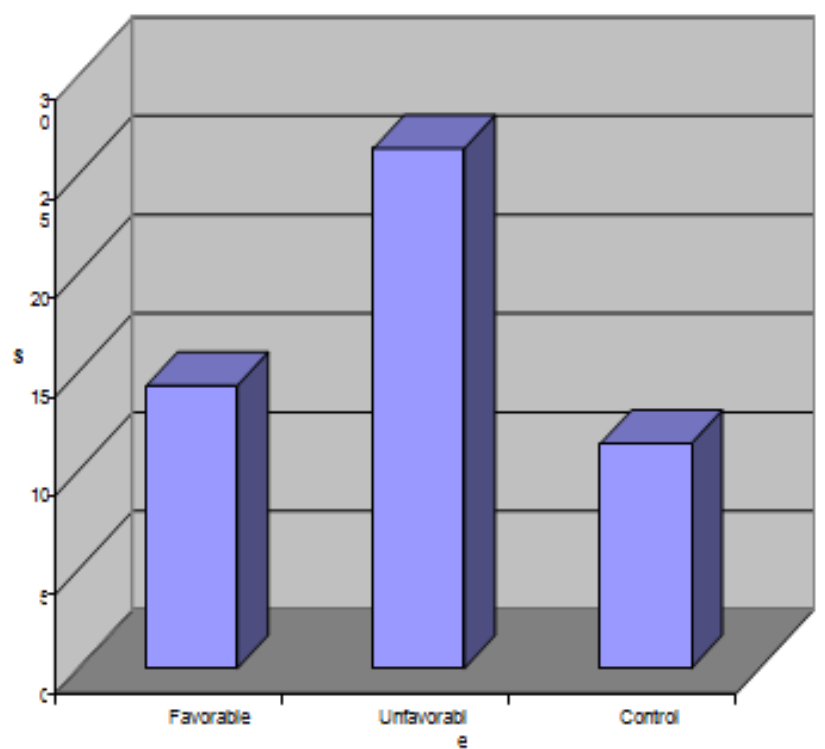

Chart (4) Means of GCS at $14^{\text {gh }}$ da)

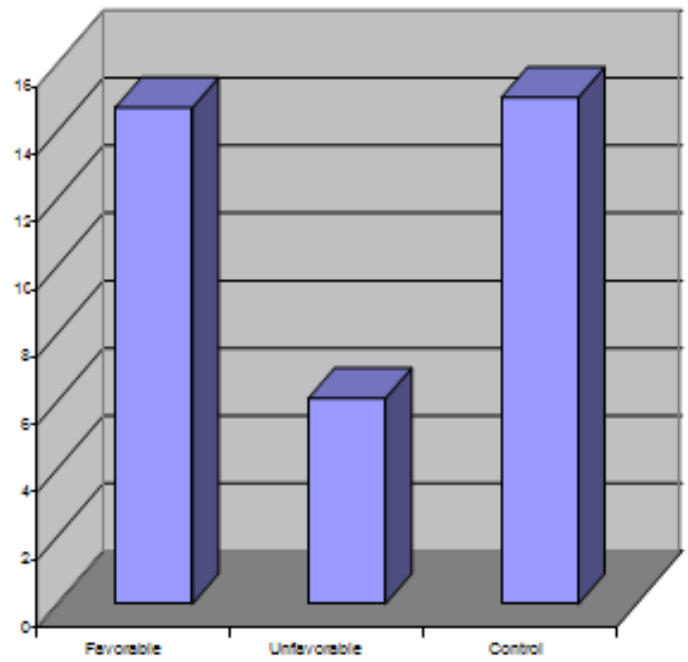

Chart (6) Meane of DIMER at $14^{\text {th }}$ daye

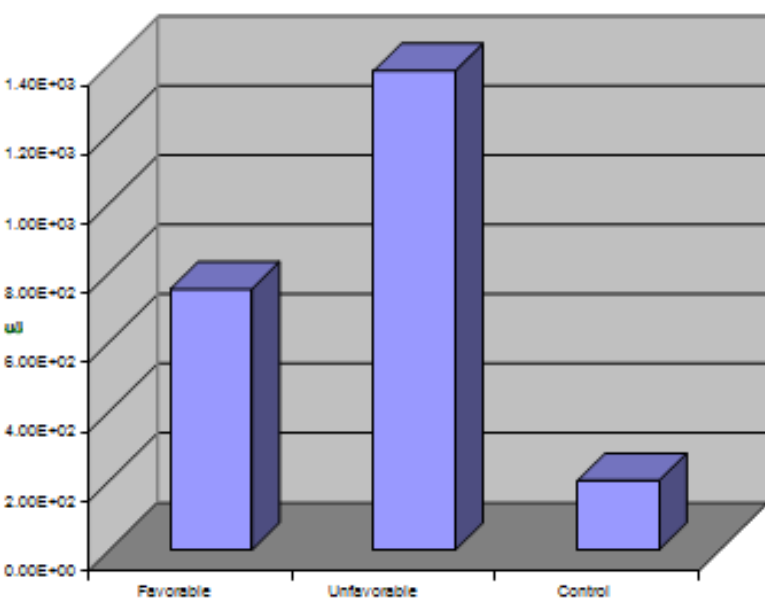

Chart (8) Meane of PT at $14^{\text {gh }}$ daye

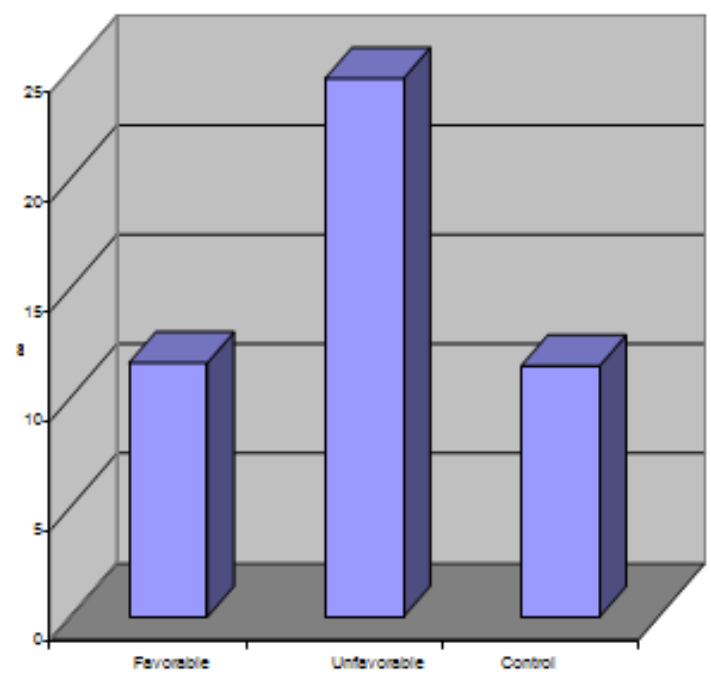




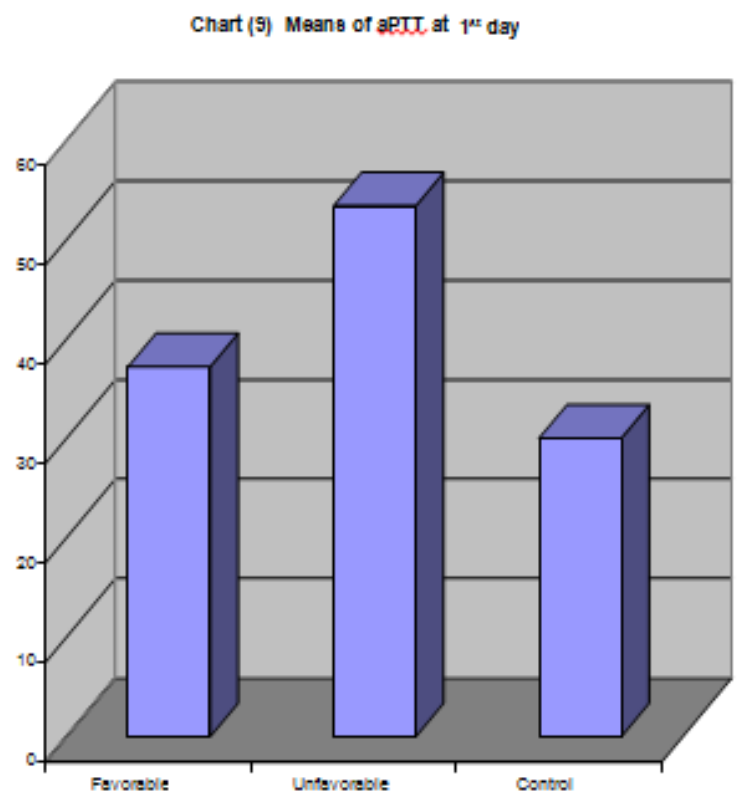

\section{DISCUSSION}

As regards sex, The males were (16 males, $69.6 \%$ in the favorable group , 10 males, $43.5 \%$ in the unfavorable group respectively and 8 males, $40 \%$ in the control group) while female gender represented 7 females $30.4 \%$ in the favorable group , 13 females $56.5 \%$ in the unfavorable group and 12 females $60 \%$ in the control group. So totally the males were $51.5 \%$ of the total cases .We found no significance statistically. Similarly in the study done by Allard, et al., (2009) ${ }^{(11)}$ who had 55 patients $(76 \%)$ of them were males, and (24\%) were females, he found no significant difference as regards sex. Also the study made by Becker, et al., (1999) ${ }^{(12)}$ on 62 patients $(41 \%$ female and 59\% males reached the same result and found no significant difference as regards sex. Study made by Bredbacka et al., (2004) ${ }^{(13)}$ agreed with this study and confirmed that no significant difference as regards sex. Also the study made by Kue, et al., (2004) ${ }^{(14)}$ was made on 98 patients with traumatic ICH (61 males and 37 females) and 59 with non-traumatic ICH (41 males and 18 females) and also found no significant difference as regards sex.

As regards weight of the patients, it ranged between 10 and $59 \mathrm{~kg}$ with a mean of $26.2174 \pm 13.11126 \mathrm{~kg}$ in the favorable group, while it ranged between 14 and $46 \mathrm{~kg}$ with a mean of $26.0870 \pm 8.63878 \mathrm{~kg}$ in the unfavorable group. While it ranged between 14 and $48 \mathrm{~kg}$ with a mean of $29.4000 \pm 11.08057 \mathrm{~kg}$ in the control group the weight while in the study made by Vavilala et al., (2001) ${ }^{(15)}$ the weight of the

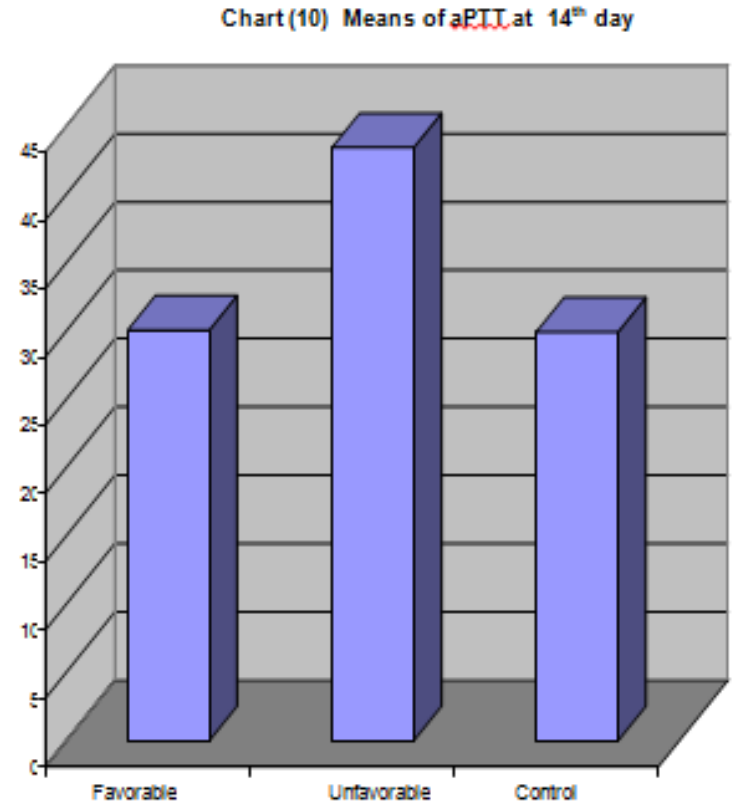

patients ranged between 7 and $46 \mathrm{~kg}$ with a mean of $19.54 \pm 8.85 \mathrm{~kg}$ in the favorable group, while it ranged between 9 and $41 \mathrm{~kg}$ with a mean of $21.40 \pm 7.54 \mathrm{~kg}$ in the unfavorable group. In our study the difference between the favorable, unfavorable and the control group as regard weights was not statistically significant similarly in the study done by Allard, et al., (2009) ${ }^{(11)}$ and by Becker, et al., (1999). ${ }^{(12)}$

As regard The diagnoses of the cases it was in the favorable group was 4 cases subdural hemorrhage $(17.4 \%), 6$ cases subarachnoid hemorrhage $(26.1 \%)$ and 13 cases intracranial hemorrhage $(56.5 \%)$ while in the un favorable group was 2 cases subdural hemorrhage (8.7\%), 2 cases subarachnoid hemorrhage $(8.7 \%), 14$ cases intracranial hemorrhage $(60.9 \%)$ and 5 cases interventricular hemorrhage (21.7\%). In the study made by Kue, et al., (2004) ${ }^{(14)}$ the diagnoses was as follow (subdural hemorrhage $35.0 \%$, epidural hemorrhage $13.3 \%$, subarachnoid hemorrhage $30.6 \%$, intracranial hematoma $18.4 \%$, and mixed hemorrhage $2.7 \%$ ), and acute non-traumatic ICH (putamen $33.9 \%$, thalamus $37.3 \%$, putaminothalamus $8.4 \%$, cerebellum $10.2 \%$, brain stem $6.8 \%$, and subcortical areas $3.4 \%$ ).

As regards $\mathrm{Hg}$ mean values showed significant changes more in the unfavorable group than the favorable group as HG showed low mean values due to loose of blood the same result was found by Becker, et al., (1999) ${ }^{(12)}$ and Murshid \& Gader (2002) (16) while HG value had no significance in the study made by Olson et al., (1999). ${ }^{(17)}$ 
GCS showed a significant successive increase in the favorable group throughout the period of the study. While in the unfavorable group GCS increased significantly gradually but yet did not affect the patient's outcome and less the favorable group. Again GCS as higher in the favorable group compared to the unfavorable group at any point of time.

The data found in this study regarding the GCS value as a prognostic indicator matches the findings in the study done by Kue, et al., (2004) (14) who found that patients in their study with GCS from 3 to 8 had poor outcome compared to those with GCS 9-12 and even better outcomes when GCS ranged between 12-15. Also, Becker, et al., (1999) ${ }^{(12)}$ found a significant association between GCS and clinical outcome in head trauma patients who developed disseminated intravascular coagulopathy (DIC). Also the study made by Vavilala et al., (2001) ${ }^{(15)}$ agreed on the data found in this study regarding the GCS value.

In the current study the mean level of D-dimer was significantly higher in the unfavorable group with mean of $(13884.67810 \pm 2.7208 \mathrm{E} 4 \mu / \mathrm{L}$, $1.0892 \mathrm{E} 4 \pm 7327.11460 \quad \mu / \mathrm{L} \quad$ and $1.3823 \mathrm{E} 3 \pm 560.58635 \mu / \mathrm{L}$ at $1^{\text {st }}$ day, $3^{\text {rd }}$ day, $14^{\text {th }}$ day respectively) than in the favorable group (4.2862E $3 \pm 2398.01345$

$\mu / \mathrm{L}$ $1.9876 \mathrm{E} 3 \pm 1079.95857 \quad \mu / \mathrm{L} \quad$ and $7.5261 \mathrm{E} 2 \pm 355.07550 \mu / \mathrm{L}$ at $1^{\text {st }}$ day, $3^{\text {rd }}$ day, $14^{\text {th }}$ day respectively), may be this was because patients in the unfavorable group were more severely injured and had a significantly lower GCS on admission (4.0435 in the unfavorable group on admission versus 9.6522 in the favorable group), and from the analysis done we can find that D-dimer difference between the unfavorable group and the favorable group gained statistical significance at $1^{\text {st }}$ day, $3^{\text {rd }}$ day and $14^{\text {th }}$ day.

While the mean values of D-dimer in the favorable group decreased from 1st day to 3rd day to 14th day and this decrease was significant which means that the more D-dimer decreases in TBI patients the better they become clinically and vice versa.

These results found in the current study are in line with the study of Kue, et al., (2004) ${ }^{(14)}$ who studied 98 TBI patients and 59 non TBI patients with ICH and made a correlation between Ddimer and GCS, pupillary light reflex, distance of midline shift on brain CT and the GOS. He excluded patients with pre existing venous thrombosis, recent surgery, drug use (asprin or Coumadin), or malignancy. They estimated the Ddimer levels within hours after acute insult and made the comparisons, they found a proportional inverse relation between initial GCS and D-dimer level in group of TBI patients, and they also found that D-dimer is correlated with poor patient outcome if $\mathrm{D}$-dimer value is $>1496 \mu / \mathrm{L}$ with sensitivity and specificity of $100 \%$ and $83 \%$ respectively. Also same finding was confirmed in studies made by Murshid \& Gader (2002) ${ }^{(16)}$ as D-dimer levels on admission were found to be slightly higher in both peripheral venous (1115 $\mu \mathrm{g} / \mathrm{ml})$ and arterial blood $(1288 \mu \mathrm{g} / \mathrm{ml})$ than in jugular venous $(888 \mu \mathrm{g} / \mathrm{ml})$ blood, but these differences were not statistically significant. Thereafter, D-dimer concentrations in the three locations dropped markedly in the three sites. All the levels recorded were very markedly higher ( $p$ $<0.0001)$ than the maximum level in healthy controls (mean: $15.9 \mu \mathrm{g} / \mathrm{ml}$; range: 1.56-60). Finding was on the same line in the study made by Bredbacka et al., (2004). ${ }^{(13)}$

D-dimer decreased significantly in the favorable group through all stages (at $1^{\text {st }}$ day, $3^{\text {rd }}$ day and $14^{\text {th }}$ day), this is concordant with the improvement in their GCS, but the decrease in the unfavorable group was noticed at day 3 and was statistically significant which is also concordant with their GCS and it also goes with the results found on correlating D-dimer with GCS and GOS as one group in which there was inverse correlation between GCS,GOS and D-dimer in day 3 and day 14 which mean that the decrease in D-dimer values thought the study was accompanied by improvement of the patients GCS and GOS. The same findings were recorded in previous studies done by Kue, et al., (2004) ${ }^{(14)}$ and Bayir et a1., (2006). ${ }^{(18)}$

Regarding the other coagulopathy parameters, we tested for PT, aPTT and INR. We found that these parameters were significantly higher in the unfavorable group than in the favorable group especially around admission and $3^{\text {rd }}$ day, and there was a correlation between mortality and increased mean values of PT, aPTT and INR.

This difference between the two groups gained statistical significance on the $1^{\text {st }}$ day in the intergroup comparison which supports other studies done for aPTT role on admission day as most of these previous studies the laboratory testing was done in the first three to four hours or merely in the first 24 hours. So these results also confirm the role of aPTT as a good predictor of poor patients' prognosis in TBI.

These results can be interpreted in several different ways, one possibility is that the coagulopathy preceded and contributed to ICH progression, this progression which normally occurs in the first 12 hours is the cause for GCS deterioration and increased odds for mortality in TBI patients and this interpretation may form a 
basis for further studying exploring whether correcting these parameters early would prevent further brain damage. But what would be the cut off value for correction at which the patients may gain the most benefit is still debated by many centers, and many other authors argue that correction of these parameters even early is fruitless and wasteful.

The second interpretation is that even though this ICH progression was most often diagnosed in the first 24 hours using serial CT scanning, but may be this progression occurred earlier preceding and perhaps contributing to the abnormal laboratory tests. So from this perspective it would be reasonable to assume that these parameters are merely a reflection for the changes that already occurred in the brain and correcting them would be useless (Oertel et al., 2004). ${ }^{(19)}$

A third assumption may be that coagulopathy and ICH progression may be a complex process in which more coagulopathy leads to $\mathrm{ICH}$ progression and vice versa in a vicious circle leading to death (Stein et al., 2004 . ${ }^{(20)}$

The studies done supporting the coagulopathy parameters PT, aPTT and INR are multiple for example, Allard, et al., (2009) ${ }^{(11)}$ investigated the role of coagulopathy in TBI and its association with mortality where he used a post-hoc analysis method in randomized controlled trial including TBI 72 patients with a GCS less than 8 with serial CT scans done for them in the first 48 hours, and blood samples where all taken in the first 24 hours for analysis. They included isolated head trauma patients, in coma, GCS less than 8, within 4 hours on injury. They excluded patients less than 16 years old, pregnant females, absent pulse victims, penetrating head injury patients, or those with minor trauma, and they found the following: all patients with prolonged aPTT, PT, INR got ICH progression with increased risk of death, while Stein et al., (2004) ${ }^{(20)}$ also made a retrospective chart review whereby he studied 253 patients with TBI and he concluded that abnormal values of INR, aPTT and platelets each independently correlated with ICH progression and mortality. Also study made by Murshid \& Gader (2002) ${ }^{(16)}$ found admission PT was notably prolonged in the three locations to almost the same extent and showed a tendency for further prolongation in the second day after injury. Thereafter, PT dropped towards normal (100\%). It was noted with interest that the APTT showed a very slight insignificant prolongation than the PT and almost normalized in the fourth day.

The study made by Oertel et al., (2004) ${ }^{(19)}$ on 142 patients found that only prolonged aPTT correlated with ICH progression. Recently
Engstrom et al., (2005) (21) retrospectively studied 27 patients with severe TBI and found that among these three laboratory tests on low platelets correlated with ICH progression and mortality.

Another study done by Bayir et a1., (2006) ${ }^{(18)}$ who were trying to determine the usefulness of fibrinolytic markers as early prognostic indicators in patients with isolated head trauma on 62 patients with GCS and PT, aPTT, platelet count, fibrinogen, fibrin degradation products (FDP) and $\mathrm{D}$-dimer were all measured in the first three hours, where a positive relationship ( $\mathrm{rs}=0.688$ ) was found between GCS and fibrinogen levels $(\mathrm{P}<0.001)$, but a markedly negative relationship between GCS and PT, PTT, FDP and D-dimer levels. Mortality strongly correlated with GCS, PT, FDP and D-dimer $(\mathrm{P}<0.001, \quad \mathrm{P}<0.001$, $\mathrm{P}<0.001$ and $\mathrm{P}<0.001$, respectively). The relationship between GCS and Platelets levels was not statistically significant $(\mathrm{P}=0.051)$. So aPTT and fibrinogen levels. A significant decrease in Plt and fibrinogen values and a significant elevation in PTT, FDP and D-dimer values were determined. A strong relationship between GCS and PT, aPTT, D-dimer as prognostic factors in TBI patients. The study made by Vavilala et al., (2001) ${ }^{(15)}$ also agreed on the same findings.

The difference between the previously mentioned studies are multiple and controversial regarding PT, aPTT, INR but most of them agreed on that the role of D-dimer is not reliable yet as prognostic factor in TBI patients and need more research.

\section{CONCLUSION}

- GCS or PGCS has evident role in evaluation and assessment of TBI especially in acute stage and gives excellent idea about the prognoses of TBI.

- D-dimer is a good marker to predict outcome in TBI \& it has an inverse correlation with GCS or PGCS. It is widely available, cheap\& reliable marker that can be easily done in most ICUs. It has definite role in prediction of poor patient outcome in TBI together with ability to mark the primary brain insult and its severity, the progression to secondary brain insult and ICH progression. It also can give us clues about which patient may die from his brain injury by reading its follow up results.

- PT, aPTT, INR and Concentration have some role in TBI and their values increase in the acute stage of TBI.

\section{RECOMMENDATIONS}

- D-dimer should be further studied to find the best time order to measure it whereby its results would much affect physician's orders and pateints management in TBI. 
- PT, aPTT, INR and Concentration need more study with trying to find which correction for their values early in the course of TBI, would give the best results in patient management.

- Routine investigations as $\mathrm{Hg}$, TLC, platelets, RBS, NA, K, SGOT, SGPT, Urea, Creatinine and Arterial blood gases need more study to use their values in the course of TBI and detect evidence role in the evaluation, diagnoses, assessment and prognoses of TBI.

- We should also try to make new researches to figure out any causal relationship between Coagulopathy, TBI and ICH progression.

- D-dimer could be used in diagnosis, follow up and prediction of poor patient outcome and mortality in TBI patients.

\section{REFERENCES}

1- Segun T. (2009); Traumatic brain injury. Definition, epidemiology and pathophysiology. [serial online]. Cited Mar 30 Available from URL: http://emedicine.medscape. Comlarticle /3 2651 0overview.

2- Langlois J, Rutland-Brown W, and Wald M. (2006): The epidemiology and impact of traumatic brain injury: a brief overview. J Head Trauma Rehabil; 21: $375-378$

3- Williamson LM, Morrison A, Stone DH. (2002): Trends in head injury mortalityamong 0-14 years old in Scotland (1986-95). J Epidemiol Comm Health; 56: 285-288.

4- Adelson PD, Bratton SL, Carney NA, Chesnut RM, Du Coudray HE, Goldstein B, et al. (2003): Guidelines for the acute medical management of severe traumatic brain injury in infants, children, and adolescents. Pediatr Crit Care Med.; 4:S49-52

5- Yeates, K. O. (2000): Closed-head injury. In K. O. Yeates, M. D. Ris, \& H. G. Taylor (Eds.), Pediatric.

6- Cassidy, J. D., Carroll, L. J., Peloso, P. M., Borg, J., von Holst, H., Holm, L., et al. (2004): Incidence, risk factors and prevention of mild traumatic brain injury: Results of the WHO Collaborating Centre Task Force on Mild Traumatic Brain Injury.

7- Hoffmann M, Ma OJ, Gaddis G: (2001): Utility of an initial D-dimer assay in screening for traumatic or spontaneous intracranial hemorrhage. Acad Emerg Med; 8: 859-65.

8- Lowe G: (2005): Fibrin D-dimer and cardiovascular risk. Semin Vasc Med; 5:387-98.

9- Kamangar, N. and McDonnell, M. (Updated 2010 May 14). Pulmonary Embolism. eMedicine [Online information]. Available online at http://emedicine. medscape. comlarticle/ 300901 - overview through http //e medicrne medscape corn Accessed August 2010.

10- Schreiber, D. (Updated 2010 June 10). Deep Venous Thrombosis and Thrombophiebitis. eMedicine [On-line information]. Available online at http://emedicine. medscape.comlarticle/758 140overview through http://emedicine.medscape.com. Accessed August 2010.

11- Allard CB, Scarpelini S, Rhind SG, Baker AJ, Shek PN, Tien H, et al (2009); Abnormal coagulation tests are associated with progression of traumatic intracranial hemorrhage. J TRAUMA 67(5):959.

12- Becker S, Schneider V, Kreuz W, Jakobi G, Scharrer I, Nowak-Gottl U. (1999); Post trauma coagulation and fibrinolysis in children suffering from severe cerebro. Cranial trauma. Eur J Pediatr 158:S197-202.

13- Bredbaeka 5, Ender G. (2004); Soluble fibrin and D-dimer as detectors of hypercoagulability in patients with isolated brain trauma. J Neurosurg Anesthesiol 6:75-82.

14- Kuo JR, Chou TJ, Chio CC, et al. (2004): Coagulopathy as a parameter to predict the outcome in head injury patients Journal of Clinical Neuroscience 11 710-4.

15- Vavilala MS, Dunbar PJ, Rivara FP, Lam AM. (2001): Coagulopathy predicts poor outcome following head injury in children less than 16 years of age. J Neurosurg Anesthesiol;13:13-8.

16- Murshid WR, Gader AG. (2002): The coagulopathy in acute head injury: Comparison of cerebral versus peripheral measurements of haemostatic activation markers. $\mathrm{Br} \mathrm{J}$ Neurosurg; 16:362-9.

17- Olson JD, Kaufman HH, Moake J, O’GormanTW, Hoots K, Wagner K, et al. (1999); The incidence and significance of hemostatic abnormalities patients with head injuries. Neurosurgery 24:82532.

18- Bayir A, et al. (2006); fibrinolytic and neurologic outcome in traumatic brain injury. Neurology India 54(7):365.

19-Oertel M, Kelly DF, McArthur D, et al., (2002): Progressive hemorrhage after head trauma: predictors and consequences of the evolving injury. J Neurosurg, 9610916.

20- Stein SC, Smith DH. (2004); Coagulopathy in traumatic intracranial injury. Neurocrit Care. 1:47988.

21- Engstrom M, Romner B, Shalen W, Reinstrup P. (2005): Thrombocytopenia predicts progressive hemorrhage after head trauma. J Neurotrauma. 22; 291-6. 


\section{دور ثنائى مد البلازما كعلامه نذير فى اصابات المخ عند الاطفال}

\author{
بكالوريوس الطب و الجر احه - جامعه الزقازيق \\ أستاذ طب الاطظفال كلية الطب - جامعة الطب - جامعة القاهرة

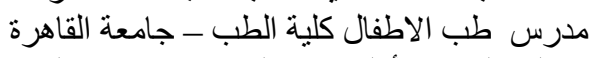

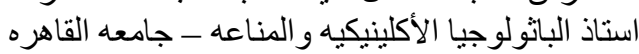

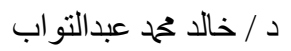 \\ د د د الد محمج أمين فؤاد \\ د د / جون رينيه لبيب البين

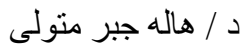

مقدمه :اصابات الدماغ هى السبب الرئيسى للوفاه والعجز بعد صدمه عصبيه حاده فى هذه الايام، هناك طلب لاستكثناف علامات التات مصليه

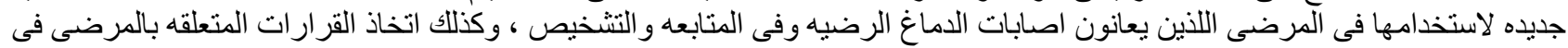

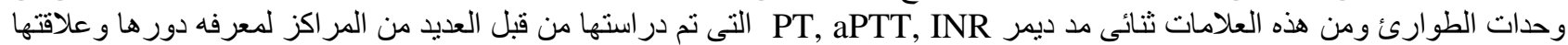

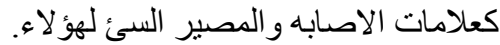

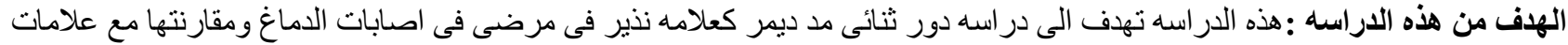

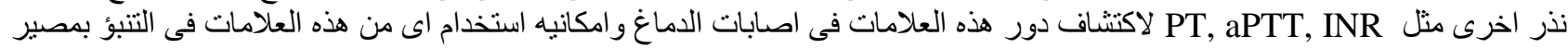

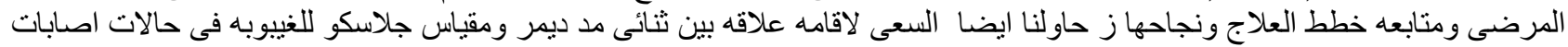

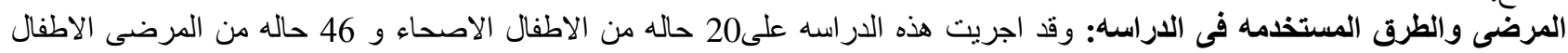

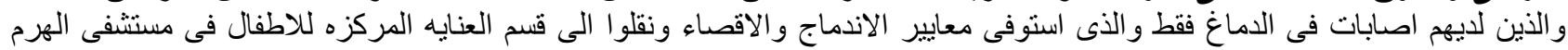

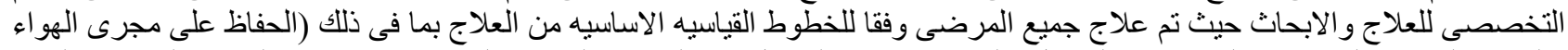

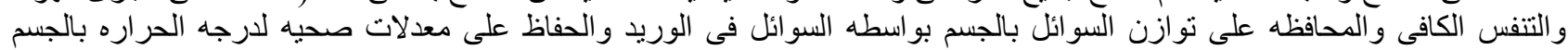

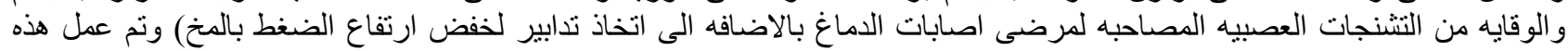

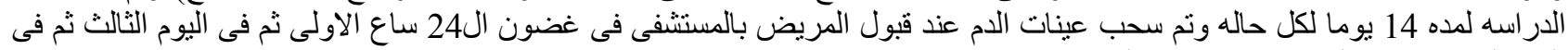

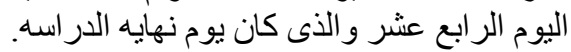

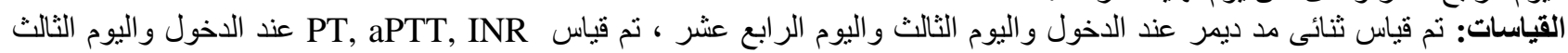

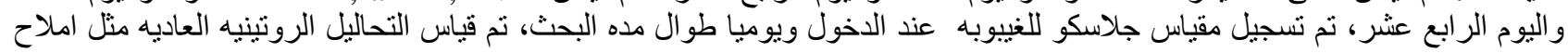

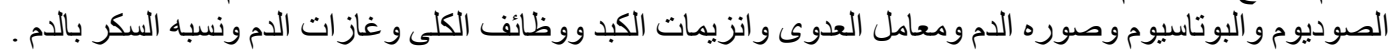

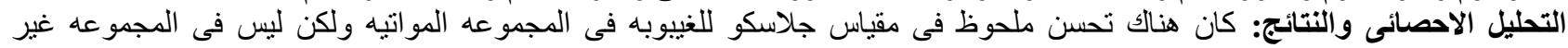

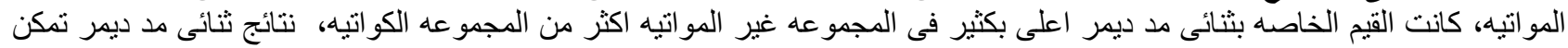

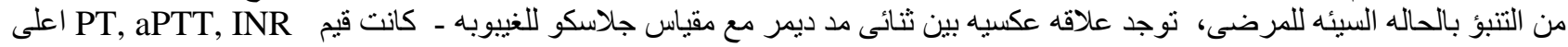

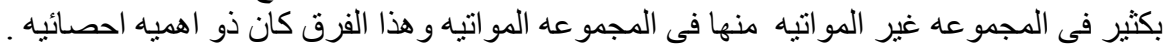

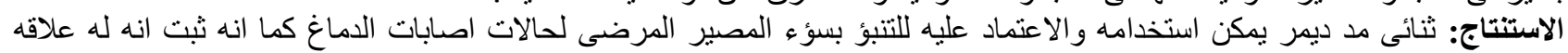

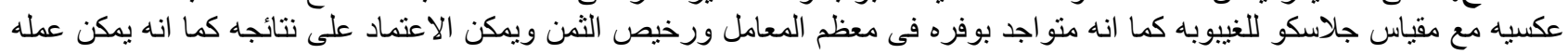

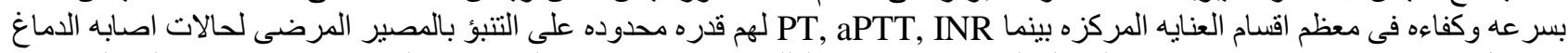

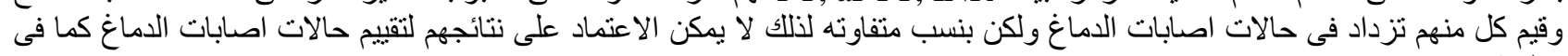

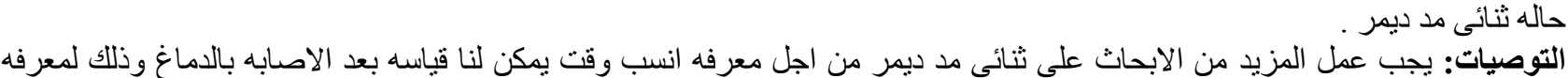

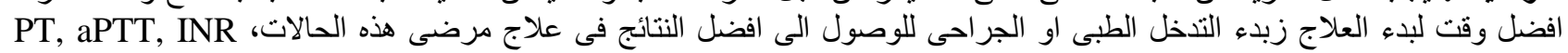

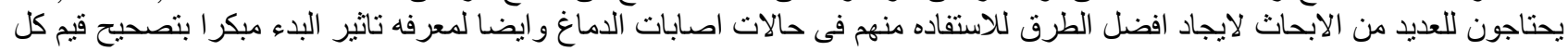

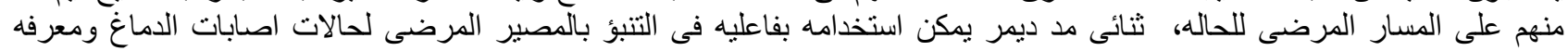
الحالات المحتمل وفاتها مبكر ال. 